\title{
Use of Fertility Awareness-Based Methods for Pregnancy Prevention Among Ghanaian Women: A Nationally Representative Cross-Sectional Survey
}

\author{
Chelsea B. Polis, ${ }^{a, b}$ Easmon Otupiri, ${ }^{c}$ Suzanne O. Bell, ${ }^{b}$ Roderick Larsen-Reindorf ${ }^{c}$
}

\section{Key Findings}

- Standard approaches underestimate fertility awareness-based method (FABM) use; we posit that at least $18 \%$ of contracepting Ghanaian women likely use an FABM.

- Economically and educationally advantaged women had higher odds of current FABM use (versus intrauterine device/hormonal method), which may suggest deliberateness of method selection (as opposed to limited access to alternatives).

- Most (92\%) rhythm users wish to improve the effectiveness of their method, and many are willing to track additional biomarkers, but only $17 \%$ ever discussed their method with a health professional.

\section{Key Implications}

- Researchers, programmers, and funders should better understand and address FABM users' needs, in commitment to reproductive autonomy and choice.

\footnotetext{
a Guttmacher Institute, New York, New York, USA.

b Johns Hopkins Bloomberg School of Public Health, Baltimore, Maryland, USA.

'School of Public Health, Kwame Nkrumah University of Science and Technology, Ghana.

Correspondence to Chelsea Polis (cpolis@guttmacher.org.)
}

\section{ABSTRACT}

Few studies in low- and middle-income countries have examined the use of fertility awareness-based methods (FABMs) for pregnancy prevention. Understanding the prevalence of FABM use among Ghanaian contraceptors and the characteristics and practices of users is essential. Our 2018 nationally representative survey of Ghanaian women included detailed questions on the use of rhythm and Standard Days Method/Cycle Beads (SDM). After considering multimethod use patterns, we estimated likely FABM prevalence among contraceptors, identified characteristics associated with current use of an FABM (vs. current use of a hormonal method/intrauterine device [IUD]), and described how women report using FABMs. At least 18\% of contracepting Ghanaian women likely use an $F A B M$, though this may be underreported. Among FABM users, $57 \%$ reported current use of an FABM alone; the remainder reported concurrent use of other methods. Women who were older, richer, more educated, and had fewer children had higher odds of current FABM use versus IUD/hormonal method. Although FABM users were more likely than other contraceptors to correctly identify the approximate fertile time, only $50 \%$ of FABM users did so correctly. Most $(92 \%)$ rhythm users were interested in making their method use more effective. While $72 \%$ had heard of SDM, less than $25 \%$ had heard of various other ways to make the rhythm method more effective. Only $17 \%$ of rhythm users had ever discussed the method with a health professional. Rhythm users indicated substantial willingness to track additional biomarkers (e.g., daily temperature or cervical mucus) or to use a phone to enhance the effectiveness of their method, and most indicated no substantial difficulty getting partners to abstain or withdraw on fertile days. A nontrivial proportion of reproductive age Ghanaian women are using an FABM, nearly all of whom are interested in learning how to improve its effectiveness. The family planning field should better address these women's contraceptive needs in commitment to reproductive autonomy and choice.

\section{INTRODUCTION}

U nderstanding the extent of people's reliance on fertility awareness-based contraceptive methods (FABMs) and the characteristics and practices of such users is essential to comprehensively meeting reproductive needs. A concise introduction to FABMs can be found elsewhere. ${ }^{1}$ In brief, FABMs aim to identify the span of days during each menstrual cycle when sexual intercourse is most likely to result in pregnancy (the 
"fertile window"). Depending on the requirements of the specific FABM, users track changes in 1 or more fertility biomarkers (e.g., menstrual start dates, basal body temperatures, cervical mucus or cervical position, and urinary hormone metabolites) in attempts to identify their fertile window during each menstrual cycle. Certain FABMs can be used to either plan or prevent pregnancy. If pregnancy prevention is desired, users can either avoid penile-vaginal intercourse or use other methods (e.g., barrier methods, withdrawal, etc.) on days the method identifies as fertile.

Such FABM users are taking action to avoid conceiving but may be more vulnerable to unintended pregnancy compared with users of certain other contraceptive methods. For example, in low-income countries, an estimated 19\% of those who report using the rhythm method (a type of FABM, described in greater detail below) will experience an unintended pregnancy in the first year of use, compared with $0.3 \%$ of implant users. $^{2}$ Contraceptive effectiveness is a key attribute for many people choosing a method, but other method characteristics influence contraceptive decision making, such as safety, side effects, impact on bleeding patterns, cost, ease of use, protection from sexually transmitted infections, privacy, etc. $^{3-7}$ Despite a common assumption that people resort to less effective contraceptive methods due to a lack of access to more effective options, these choices often reflect user preferences. ${ }^{8-13}$ For example, side effects and health concerns are the most common reasons for nonuse or discontinuation of hormonal contraception among women in low-income countries who do not desire pregnancy, ${ }^{14,15}$ whereas methods perceived as "natural" may appeal to people with these concerns. ${ }^{12}$

FABMs have received relatively limited attention in the contraceptive literature. Rhythm is perhaps the most widely known FABM, although many who report using rhythm are not likely using its formal requirements. ${ }^{16}$ Relatively little is known about how those who identify as rhythm users actually use the method and the extent to which they rely on other contraceptive methods during the fertile window versus abstaining from sex during this period (i.e., practice periodic abstinence). Rhythm is typically classified as a traditional method. However, certain other FABMs (e.g., Standard Days Method [SDM], TwoDay Method, etc.) are often classified as modernalthough these classifications are not universal (e.g., the United Nations Population Division does not classify these methods as modern) - and the nomenclature is imperfect. ${ }^{17-21}$ In addition to
FABMs, some people use menstrual tracking smartphone apps or devices to time sexual intercourse for pregnancy prevention. Although 2 apps have received clearance from the United States Food and Drug Administration for use as a contraceptive method (Natural Cycles in 2018, ${ }^{22}$ which also received CE Marking in Europe, and Clue in $2021^{23}$ ), most such apps or devices are not tested or indicated for this purpose and may offer predictions of unknown accuracy regarding the timing of fertile days. ${ }^{24,25}$

Research focused specifically on FABM use in low- and middle-income countries (LMICs) has been particularly limited (with exceptions from the United States Agency for International Development and the Institute for Reproductive Health at Georgetown University $\left.{ }^{18,26-31}\right)$. However, there are existing and emerging reasons for greater understanding around FABM use in LMICs. First, our understanding of contraceptive decision making is incomplete without understanding people who select contraceptive options that are not among the most highly effective. Understanding such choices can help to support client-centered approaches to contraceptive counseling, programming, and method development. Second, FABMs use is increasing in some contexts, ${ }^{32}$ and multiple researchers have identified substantial underestimation of methods (including rhythm) in nationally representative surveys. $^{12,13,33-35}$ This suggests incomplete existing information on the prevalence of FABM use, which impacts our understanding of who chooses FABMs and impacts estimation of other key metrics (e.g., unmet need for contraception). Third, without understanding how people employ these methods, we have little ability to identify approaches that enhance the effectiveness of their contraceptive practices while respecting their contraceptive preferences.

Additional reasons for understanding FABM use in LMICs have emerged more recently. First, the coronavirus disease (COVID-19) pandemic has limited access to contraceptive services, prompting calls by some international organizations for counseling on FABMs, ${ }^{36}$ which are less vulnerable than other methods to commodity supply chain disruptions. ${ }^{37}$ Furthermore, there is an increasing understanding of the application of principles of self-care to sexual and reproductive health worldwide, ${ }^{38}$ as well as emerging literature on whether fertility knowledge (e.g., regarding the timing of ovulation or impacts of age on fertility) impacts reproductive outcomes. ${ }^{39,40}$ Although FABMs are not appropriate for all individuals, they can assist certain couples to avoid (or seek)

\section{Our \\ understanding of contraceptive decision making is incomplete without understanding people who select contraceptive options that are not among the most highly effective.}




We aimed to
estimate the
prevalence of
FABM use among
Ghanaian
contraceptors,
understand
characteristics
associated with
choosing an
FABM, and collect
information on
how Ghanaian
women use
FABMs.

We aimed to estimate the prevalence of FABM use among understand characteristics associated with choosing an FABM, and collect information on how Ghanaian FABMs. pregnancy with limited or no clinical support after being trained in and correctly using the method. Finally, the increasing development of new technologies will continue to provide new tools that facilitate use of FABMs and may increase their prevalence. The contraceptive field can play a useful role in helping people who prefer a method they may perceive as "natural" in understanding if new technologies have reliable evidence on contraceptive effectiveness ${ }^{41}$ and to optimize the effectiveness of chosen methods.

To expand understanding of FABM use in LMICs, we aimed to examine the use of 2 FABMs (rhythm method and SDM/CycleBeads) in a nationally representative sample of Ghanaian women. Our objectives were to estimate the prevalence of FABM use among Ghanaian contraceptors (including careful consideration of multimethod use patterns), understand characteristics associated with choosing an FABM (relative to choosing an intrauterine device [IUD] or hormonal method), and collect detailed information on various aspects of how Ghanaian women use FABMs. This article also aims to contribute to improvements in measuring FABM use across diverse contexts by detailing methodological considerations around terminology and definitions used for FABMs in large-scale surveys and how these might be improved.

\section{METHODS}

\section{Survey Design and Implementation}

Our survey design and sampling have been described in detail elsewhere. ${ }^{42}$ Briefly, data for this analysis were drawn from a nationally representative, community-based survey of reproductiveaged (15-49 years) women in Ghana $(\mathrm{N}=4,722)$, conducted in 2018 as part of a larger study on abortion incidence in Ghana. ${ }^{43}$ The survey was a collaborative effort between the Guttmacher Institute, the Kwame Nkrumah University of Science and Technology (KNUST), and the Performance Monitoring and Accountability 2020 team at the Johns Hopkins Bloomberg School of Public Health. We used a multistage stratified cluster sampling design and probability-proportionalto-size sampling to select 100 enumeration areas, each consisting of approximately 200 households. We then listed, mapped, and randomly selected 42 households in each selected enumeration area. In those households, we conducted a short household survey to collect socioeconomic information and to identify eligible female respondents. We invited all eligible women to give informed consent and participate in the full survey. Trained resident enumerators collected data for both surveys in a private area, using an Android smartphone enabled with Open Data Kit electronic data collection software. Households with one or more participating respondents who completed the full survey received a bar of soap. The Institutional Review Boards of the Guttmacher Institute, the KNUST Committee on Human Research, Publication and Ethics, and the Johns Hopkins Bloomberg School of Public Health provided ethical approval. Prior analyses of these data showed that among all respondents aged 15-49 years in our sample who had ever had sex $(n=4,139), 33.7 \%$ currently reported using any contraceptive method. ${ }^{44}$

\section{Identifying Rhythm or SDM Users}

Traditional methods and modern FABMs are likely underreported in many surveys, including Demographic and Health Surveys (DHS). Studies suggest that some respondents interpret filtering questions (e.g., "are you or your partner currently doing something or using any method to delay or avoid getting pregnant?") as pertaining only to modern or non-"natural" methods. ${ }^{12,13,33,34}$ Additionally, when asked to spontaneously name methods used, a qualitative study of 48 Ghanaian women found that "fertility awareness methods were rarely spontaneously mentioned as a way to prevent pregnancy...yet counting days was almost universally used at one time or another and participants described it as a taken-for-granted part of a woman's life." 34 Other studies suggest that women using multiple methods (e.g., an FABM with condoms during the fertile window) may potentially report only condom use, ${ }^{12}$ unless, for example, she is asked about the use of all potential methods.

Our study did not address the first concern as we did use the filtering question, but it did address the second concern by asking about the use of each method among those who affirmed using a method. Specifically, survey respondents were asked, "Have you or a partner ever done something or used any method to delay or avoid getting pregnant?" We asked respondents who said "yes" to spontaneously list methods ever used, and then the interviewer asked about each of the possible methods to capture users who self-identified as using any of these methods (female and male sterilization, implants, IUDs, injectables (3 month and 1 month), pill, emergency contraception (EC), male and female condoms, diaphragm, foam or jelly, SDM/Cycle Beads, lactational amenorrhea 
method, N-tablet, rhythm method, withdrawal, washing, or "other traditional method"). The interviewer next followed a similar process for current method use by asking nonpregnant women, "Are you or your partner currently doing something or using any method to delay or avoid getting pregnant?" Again, we only asked respondents who said "yes" to list methods currently used, before being asked about each possible method, to self-identify as current users.

Like DHS and other surveys, our survey may suffer from underreporting of traditional or "natural" methods, if respondents answered "no" to both filtering questions under the assumption that traditional or "natural" methods do not count. Therefore, we interpret our prevalence estimates as a lower bound. However, each respondent who acknowledged ever or currently doing something or using any method to delay or avoid pregnancy was probed on all possible contraceptive methods.

\section{Data Analysis} based upon the most effective method a person reports currently using. For example, each DHS survey contains a hierarchical list of methods, ordered by typical use contraceptive effectiveness using both SDM and condoms, she is considered a condom user in prevalence estimation. This approach may underestimate FABM prevalence, as some FABM users use barrier methods or EC during the fertile window ${ }^{34,45}$ and would thus be coded as a barrier or EC user, despite having sex with no contraception on days that the method (correctly or incorrectly) identifies as infertile.

To address this underestimation issue, we used an approach previously applied to data from the United States ${ }^{46}$ to estimate likely FABM prevalence among Ghanaian contraceptors. First, we calculated a standard prevalence estimate based on "most effective" method (using the ordering represented in Table 1); as already noted, this approach may underestimate FABM use. Next, we recalculated prevalence, incorporating information on multiple method use. That is, a person who reported currently using 2 or more methods would be included in all reported method categories for method-specific prevalence estimation. These are likely overestimates since some women use an FABM with a highly effective method (such as sterilization, an IUD, or hormonal contraception), which likely serves as their primary mode of contraception. Therefore, to identify the most likely FABM prevalence estimate, it is necessary to examine specific patterns of multiple method use among FABM users. We classified respondents who reported any current use of an FABM into 3 categories:

- Category A: Reported current use of an FABM alone or with current use of a less effective method (i.e., withdrawal, washing, etc.)

- Category B: Reported current use of an FABM in conjunction with current use of barrier methods and/or EC

- Category C: Reported current use of an FABM in conjunction with current use of a highly effective method (i.e., hormonal contraception, an IUD, or sterilization).

As in a prior study, ${ }^{46}$ we considered women in Category A as definite FABM users, women in Category B as likely FABM users, and women in Category $\mathrm{C}$ as relying primarily on a highly effective (non-FABM) method. Thus, we included women in Categories A or B in our FABM prevalence estimation.

We calculated prevalence estimates among "contraceptors,"* excluding women who: did not report that they (or their partner) were "currently doing something or using any method to delay or avoid getting pregnant"; women who were currently trying for pregnancy, women who were currently pregnant, and women who reported never having had sexual intercourse. We considered the remaining 1,165 participants "contraceptors."

Next, we conducted bivariate and multivariable logistic regressions to identify characteristics we hypothesized to be associated with being a current (definite or likely) FABM user versus a current user of hormonal contraceptives or an IUD, and that were available in these data. Characteristics we examined included ecological zone (Northern, Middle, Central), residence (urban vs. rural), age (continuous), marital status (currently married/cohabiting, formerly married or cohabiting, never married or cohabiting), parity (continuous), education (none, primary or middle, secondary), religion (none, any Christian, Muslim, traditional/other), wealth (poorest $60 \%$ vs. richest $40 \%$ ), importance of avoiding a pregnancy now (very important, somewhat important, not at all important), and correct knowledge of approximate fertility time (incorrect vs. correct). We present a multivariable model including all variables hypothesized to be relevant (a sensitivity

*For comparability to other existing estimates, we also calculated contraceptive prevalence among all women, married women, and sexually active unmarried women (Supplement A).
Method-specific prevalence is typically calculated estimates. If a DHS respondent reports currently

\section{Method-specific prevalence is typically calculated based on the most effective method a person reports currently using, but this approach may underestimate FABM prevalence.}


TABLE 1. Percent Distribution of Contraceptors ${ }^{a}$ Aged 15-49, by Current Contraceptive Method(s) Used at Interview, Ghana, 2018

\begin{tabular}{|c|c|c|}
\hline & $\begin{array}{c}\text { Among Contraceptors (Unweighted } n=1,165), \\
\text { by Most Effective Method Reported } \\
\text { Weighted \% and } 95 \% \mathrm{Cl}\end{array}$ & $\begin{array}{l}\text { Among Contraceptors (Unweighted } \mathrm{n}=1,165 \text { ), } \\
\text { By All Methods Reported } \\
\text { Weighted \% and } 95 \% \mathrm{Cl}^{\mathrm{b}}\end{array}$ \\
\hline Female sterilization & $3.5(2.4,5.0)$ & $3.5(2.4,5.0)$ \\
\hline \multicolumn{3}{|l|}{ Hormonal methods } \\
\hline Implant & $22.9(19.6,26.7)$ & $22.9(19.6,26.7)$ \\
\hline Intrauterine device & $2.5(1.6,4.0)$ & $2.6(1.6,4.1)$ \\
\hline 3-month injectables & $19.2(16.7,22.0)$ & $20.4(17.8,23.3)$ \\
\hline 1-month injectables & $1.7(1.1,2.7)$ & $2.0(1.3,3.1)$ \\
\hline Pill & $12.3(10.0,15.0)$ & $13.8(11.3,16.8)$ \\
\hline Emergency contraception & $7.5(5.7,9.7)$ & $8.2(6.3,10.4)$ \\
\hline \multicolumn{3}{|l|}{ Condoms } \\
\hline Male condom & $7.8(6.1,9.8)$ & $11.8(9.6,14.3)$ \\
\hline Female condom & $0.1(0.0,1.1)$ & $0.3(0.1,1.0)$ \\
\hline \multicolumn{3}{|l|}{ Traditional methods and FABMs } \\
\hline Standard Days Method & $4.3(2.5,7.1)$ & $6.0(3.7,9.4)$ \\
\hline Lactational Amenorrhea Method & $0.9(0.5,1.8)$ & $1.0(0.5,1.9)$ \\
\hline Rhythm & $9.2(6.9,12.3)$ & $13.6(10.5,17.3)$ \\
\hline Withdrawal & $3.4(2.2,5.1)$ & $12.5(9.7,15.9)$ \\
\hline $\mathrm{N}$-Tablet ${ }^{\mathrm{c}}$ & $2.1(1.1,4.0)$ & $3.6(2.1,5.9)$ \\
\hline Washing & $0.3(0.0,0.9)$ & $2.4(1.3,4.4)$ \\
\hline Other traditional methods (unspecified) & $2.3(1.4,3.6)$ & $3.0(2.1,4.5)$ \\
\hline
\end{tabular}

Abbreviations: Cl, confidence interval; FABM, fertility awareness-based method

a Denominator includes women who reported currently using contraception, being sexually experienced, not being currently pregnant, and not currently trying for pregnancy.

${ }^{b}$ Indicates percent of all contraceptive users that reported using this method at the time of interview, either individually or as part of multiple method use.

Percentages do not sum to 100\% because more than one method may have been used at the time of interview. Respondents could list as many methods as necessary.

c N-Tablet refers to Primolut N, a norethisterone pill approved for treating menstrual disorders, which women in Ghana report using as a peri-coital contraceptive method, despite a lack of evidence that it is effective or safe for contraceptive use.

Note: No participants reported that they or their partner was currently using male sterilization, diaphragm, or foam/jelly.

analysis demonstrated similar results when including only those variables significant at $P \leq .05)$. Finally, we calculated descriptive statistics on a series of detailed questions asking FABM users about their knowledge of and ways in which they practice FABMs.

We performed analysis in Stata version 16, accounting for the complex survey design using survey weights to adjust for the probability of selection and the Taylor Linearization method to calculate standard errors that correctly account for Our data revealed clustering. We also used the subpop option to restrict a diverse range of to appropriate analytic populations.

\section{FABM method use} patterns.

\section{RESULTS}

\section{FABM Prevalence Among Contraceptors}

Among contraceptors, 9.2\% reported rhythm and $4.3 \%$ reported SDM as their most effective method (Table 1). As previously noted, these are likely underestimates. Calculating prevalence among contraceptors based on all methods reported increased rhythm prevalence to $13.6 \%$ and SDM prevalence to $6 \%$ (Table 1 ). As mentioned, these are likely overestimates, so we examined specific patterns of multimethod use among FABM users.

Our data revealed a diverse range of FABM method use patterns. Among all women who 
TABLE 2. Use Patterns Among Women Reporting Current Use of Rhythm or SDM, With or Without Current Use of Other Methods

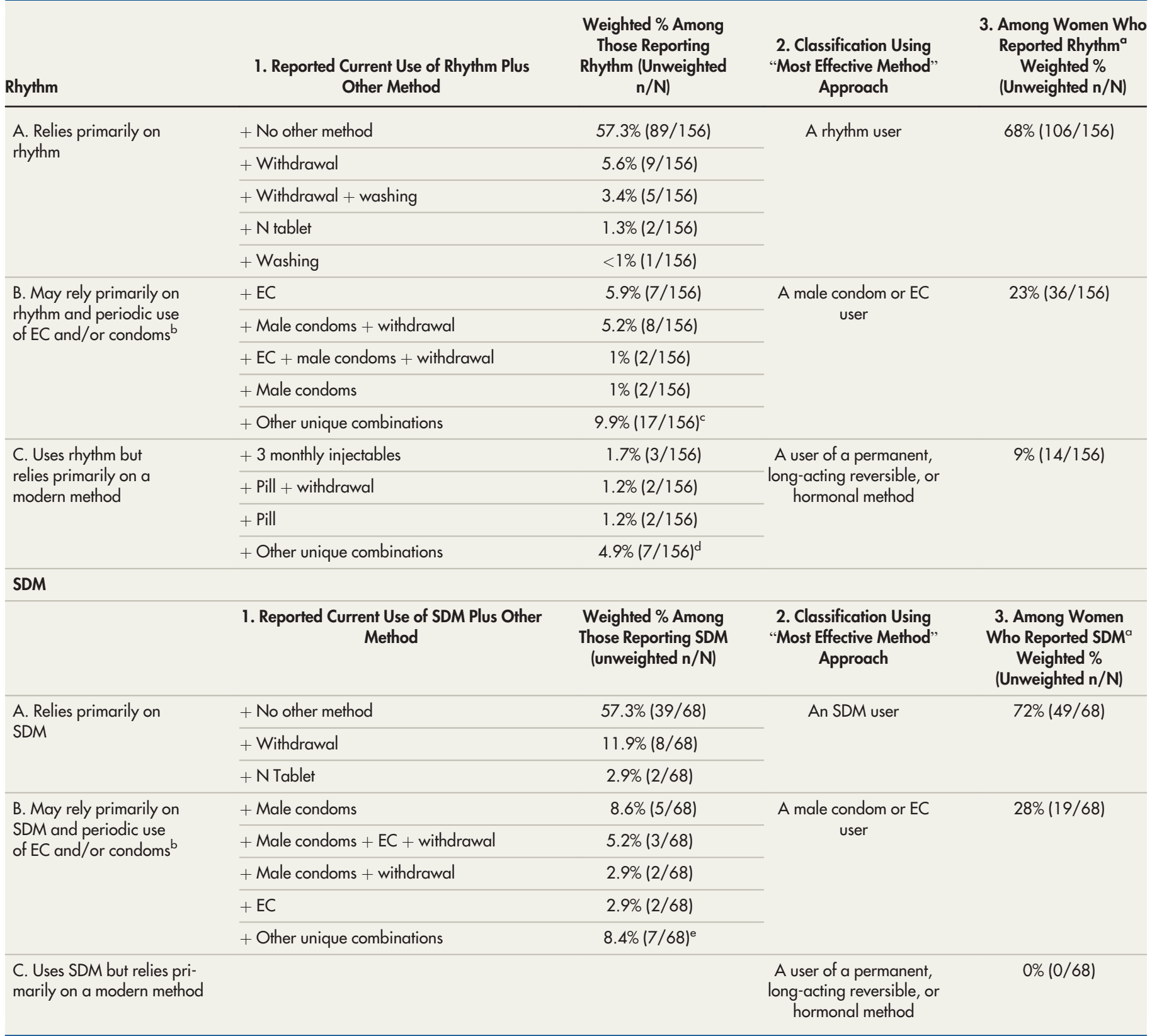

Abbreviations: EC, emergency contraception; SDM, Standard Days Method.

"Who would be classified as per label in column 2, if using the "most effective method" classification approach.

${ }^{b} 4$ women reported using both rhythm and SDM, so they may rely primarily on either FABM. In DHS they would be classified as an SDM user.

"Rhythm plus male condoms and/or EC, and potentially one or more of the following: withdrawal, washing, other traditional method, or SDM.

dRhythm plus 2 or more of the following: implants, 3 monthly injectables, pill, male condoms, LAM, EC, withdrawal, washing.

e SDM plus male condoms and/or EC, and potentially one or more of the following: rhythm, withdrawal, N Tablet.

reported currently using rhythm or SDM, over half $(57.3 \%)$ reported using that FABM without any additional methods (Table 2 ). The next most common pattern of multimethod use among rhythm users involved either EC or withdrawal (among
$5.9 \%$ and $5.6 \%$ of women who reported rhythm use, respectively), and among SDM users, involved either withdrawal or male condoms (among $11.9 \%$ and $8.6 \%$ of women who reported SDM, respectively). If classified by 
TABLE 3. Prevalence of FABMs by Estimation Method and Population Subgroup

\begin{tabular}{|c|c|c|c|c|c|c|}
\hline & \multicolumn{2}{|c|}{$\begin{array}{c}\text { Rhythm } \\
\%(95 \% \mathrm{Cl})\end{array}$} & \multicolumn{2}{|c|}{$\begin{array}{c}\text { SDM } \\
\%(95 \% \mathrm{CI})\end{array}$} & \multicolumn{2}{|c|}{$\begin{array}{c}\text { Either }^{\mathrm{b}} \\
\%(95 \% \mathrm{Cl})\end{array}$} \\
\hline & $\begin{array}{l}\text { "Most Effective } \\
\text { Method" } \\
\text { Estimation } \\
\text { Approach }\end{array}$ & $\begin{array}{c}\text { Our } \\
\text { Estimation } \\
\text { Approach }^{a}\end{array}$ & $\begin{array}{l}\text { "Most Effective } \\
\text { Method" } \\
\text { Estimation } \\
\text { Approach }\end{array}$ & $\begin{array}{c}\text { Our } \\
\text { Estimation } \\
\text { Approach }^{a}\end{array}$ & $\begin{array}{l}\text { "Most Effective } \\
\text { Method" } \\
\text { Estimation } \\
\text { Approach }\end{array}$ & $\begin{array}{l}\text { Our Estimation } \\
\text { Approach }^{\text {a }}\end{array}$ \\
\hline $\begin{array}{l}\text { Sexually active (within last } \\
30 \text { days) unmarried women }\end{array}$ & $3.6(1.7,7.1)$ & $6.8(3.9,11.4)$ & $1.4(0.5,4.0)$ & $1.6(0.6,4.0)$ & $5.0(2.8,8.6)$ & $8.2(5.2,12.6)$ \\
\hline Contraceptors & $9.2(6.9,12.3)$ & $12.4(9.5,15.9)$ & $4.3(2.5,7.1)$ & $6.0(3.7,9.4)$ & $13.5(10.9,16.7)$ & $18.1(14.9,21.8)$ \\
\hline
\end{tabular}

Abbreviations: Cl, confidence interval; FABM, fertility awareness-based method; SDM, Standard Days Method.

${ }^{a}$ Incorporating information on multiple method use. This approach assumes that women in Categories A and B in Table 2 rely primarily on an FABM and may routinely or occasionally use condoms and/or EC during days they believe to be fertile.

"The "either" category does not always equal the sum of the "rhythm" and "SDM" category due to a small number of women who reported both methods.

most effective method, $68 \%$ and $72 \%$ of women who reported currently using rhythm or SDM, respectively, would be classified as a user of the FABM they reported (Table 2, category A). Approximately $23 \%$ and $28 \%$ of women who reported using rhythm or SDM, respectively, would be classified as either a user of male condoms or EC using the standard prevalence estimation approach; though these women may rely primarily on an FABM and use condoms and/or EC episodically during their presumed fertile window (Table 2, category B). Finally, $9 \%$ of women who reported using rhythm (and $0 \%$ of women who reported using SDM), reported also currently using a permanent, long-acting reversible, or hormonal method, and would be classified as a user of that more highly effective method using the standard prevalence estimation approach (Table 2, category $\mathrm{C})$.

We assumed that respondents in categories $\mathrm{A}$ and B (Table 2) should be counted as FABM users, suggesting that at least $18.1 \%$ of contraceptors in Ghana relied primarily on an FABM, whether modern (SDM: 6\%) or traditional (rhythm: $12.4 \%$ ) (Table 3). In other words, taking multiple method use (i.e., among women using an FABM plus (fe)male condoms and/or EC) into account increased the percentage of women who likely relied on an FABM from $13.5 \%$ (95\% confidence interval $[\mathrm{CI}]=10.9,16.7$, and composed of $9.2 \%$ rhythm users and $4.3 \%$ SDM users) to $18.1 \%$ $(95 \% \mathrm{CI}=14.9,21.8)$.

\section{Characteristics Associated With FABM Use vs. Hormonal Contraception/IUD Use}

In bivariate analyses, factors associated with approximately twice the odds of FABM use relative to hormonal contraception/IUD use included: living in the Middle or Central zone (vs. Northern zone), having never been (vs. currently being) married or cohabitating, feeling that avoiding pregnancy now was not at all (vs. very) important, identifying with any Christian religion (vs. no religion), and correctly identifying the approximate fertile time (vs. not knowing or correctly identifying it) (Table 4). Living in an urban (vs. rural) area and being in the richest $40 \%$ (vs. poorest $60 \%$ ) of the population were associated with approximately 3 times the odds. Having attended secondary school (vs. no school) was associated with over 4 times the odds of FABM use (vs. hormonal contraception/IUD use). Each additional child born was associated with $20 \%$ lower odds of FABM use. Age was not significantly associated with FABM use.

In multivariable analysis, factors significantly associated with FABM use (vs. hormonal contraception/IUD use) included: age (each year was associated with an increase in odds of FABM use by $10 \%$ ), parity (each child was associated with a decrease in odds of FABM use by $30 \%$ ), and being richer or having attended secondary school or higher, each of which was associated with approximately double the odds of FABM use (Table 4). Feeling that avoiding pregnancy was not at all 
TABLE 4. Odds Ratio Associated With Use of an FABM Relative to Use of Hormonal Contraception or an IUD

\begin{tabular}{|c|c|c|c|c|}
\hline & \multicolumn{4}{|c|}{$\begin{array}{l}\text { Use of an FABM } \\
\text { (Relative to Use of Hormonal } \\
\text { Contraception/IUD) }\end{array}$} \\
\hline & \multicolumn{2}{|c|}{$\begin{array}{l}\text { Unadjusted } \\
\text { Model }\end{array}$} & \multicolumn{2}{|c|}{$\begin{array}{l}\text { Adjusted } \\
\text { Model }^{ \pm}\end{array}$} \\
\hline & OR & $95 \% \mathrm{Cl}$ & OR & $95 \% \mathrm{Cl}$ \\
\hline \multicolumn{5}{|l|}{ Zone (ref :Northern) } \\
\hline Middle & $1.9^{\mathrm{b}}$ & $1.0,3.5$ & 1.5 & $0.7,3.4$ \\
\hline Central & $2.0^{b}$ & $1.1,3.8$ & 1.1 & $0.4,2.8$ \\
\hline \multicolumn{5}{|l|}{ Residence (ref: rural) } \\
\hline Urban & $2.7^{c}$ & $1.5,4.7$ & 1.2 & $0.6,2.4$ \\
\hline Age (continuous) & 1.0 & $0.9,1.0$ & $1.1^{\mathrm{c}}$ & $1.0,1.1$ \\
\hline \multicolumn{5}{|c|}{ Union/marital status (ref: currently married/cohabitating) } \\
\hline Formerly married or cohabitating & 0.7 & $0.3,1.5$ & 0.6 & $0.2,1.3$ \\
\hline Never married or cohabitating & $2.3^{d}$ & $1.3,4.0$ & 1.5 & $0.8,2.9$ \\
\hline Parity (continuous) & $0.8^{c}$ & $0.7,0.9$ & $0.7^{c}$ & $0.6,0.8$ \\
\hline \multicolumn{5}{|l|}{ Education (ref: none) } \\
\hline Attended primary or middle & 1.7 & $1.0,3.0$ & 1.4 & $0.8,2.5$ \\
\hline Attended secondary & $4.4^{c}$ & $2.3,8.6$ & $2.1^{\mathrm{b}}$ & $1.1,4.1$ \\
\hline \multicolumn{5}{|l|}{ Religion (ref: no religion) } \\
\hline Any Christian & $2.0^{b}$ & $1.1,4.0$ & 1.1 & $0.6,2.3$ \\
\hline Muslim & 1.5 & $0.7,3.3$ & 1.2 & $0.4,3.3$ \\
\hline Traditional religion/other & 0.3 & $0.1,1.1$ & 0.3 & $0.1,1.2$ \\
\hline \multicolumn{5}{|l|}{ Wealth (ref: poorest 60\%) } \\
\hline Richest $40 \%$ & $3.0^{c}$ & $2.0,4.5$ & $1.7^{b}$ & $1.0,2.7$ \\
\hline \multicolumn{5}{|c|}{ Importance of avoiding pregnancy now (ref: very important) } \\
\hline Not at all important & $1.8^{\mathrm{b}}$ & $1.0,3.2$ & 1.9 & $0.9,3.7$ \\
\hline Somewhat important & 1.3 & $0.6,2.7$ & 1.3 & $0.6,3.2$ \\
\hline \multicolumn{5}{|c|}{ Correct knowledge of approximate fertile time (ref: incorrect knowledge) } \\
\hline Correct & $1.9^{d}$ & $1.2,3.1$ & 1.5 & $0.9,2.6$ \\
\hline
\end{tabular}

important and correct knowledge of the approximate fertile time were associated with an elevated odds ratio in bivariate analysis but did not reach statistical significance at $P \leq .05$ in multivariable analysis.

Interestingly, among contraceptors, $34 \%$ of those not using an FABM and $50 \%$ of FABM users correctly identified the approximate fertile time (i.e., "halfway between 2 periods") ( $P$-value for $\mathrm{chi}^{2}=0.01$, Supplement B). It is also worth noting that most ( $80 \%)$ FABM users felt it was "very important" for them to avoid pregnancy now (Supplement B). 


\section{How Women Report Using the Rhythm Method}

The vast majority $(85 \%)$ of rhythm users noted that they identify their fertile and nonfertile days by counting days of a menstrual cycle using a calendar (Supplement C) (participants could report more than 1 response). We did not obtain more detailed information on which rules, specifically, were used to determine fertile days using a calendar. About 1 in 6 rhythm users $(17 \%)$ used an unspecified approach to determine her fertile window, and $9 \%$ did so by observing changes in cervical mucus. Alternative approaches were reported by $5 \%$ or less of rhythm users: using a mobile phone app (5\%), observing the position or texture of their cervix $(3 \%)$, recording daily temperature $(1 \%)$, or using CycleBeads to determine her fertile days $(0 \%)$.

Among rhythm users, $12 \%$ believed there was no chance of getting pregnant over the course of a year while using the method, and $64 \%$ reported believing that there was a $\geq 50 \%$ chance.

Nearly three-quarters $(72 \%)$ of rhythm users had heard of the SDM. Less than one-quarter had heard of ways to make FABMs easier to use, such as CycleBeads (22\%) or the CycleBeads mobile app $(17 \%)$, other mobile FABM apps $(23 \%)$, or other simple-to-use FABMs like TwoDay method $(22 \%)$.

Nearly all rhythm users (92\%) expressed in-

We posit that at
least $18 \%$ of
contracepting
women in Ghana
likely relied
primarily on an
FABM for
pregnancy
prevention.

terest in learning how to make the rhythm method more effective at pregnancy prevention. Among women who wanted to make their rhythm use more effective (and were not already using the given approach mentioned), a majority would be willing to learn about approaches facilitated by a phone $(82 \%)$ or to record their daily temperature $(76 \%)$. Slightly over half $(53 \%)$ expressed a willingness to collect their cervical mucus daily or to observe the texture of their cervix by inserting their fingers into their vagina daily.

Only half of rhythm users knew where to go for advice on using rhythm effectively. Among those who knew, most (53\%) would go to a family planning service provider. However, only $17 \%$ of rhythm users had ever discussed using the rhythm method with a health professional.

\section{How Women Report Using FABMs (Rhythm or SDM) Overall}

When FABM users were asked how they avoided pregnancy on days identified as fertile (and permitted to list as many responses as desired), $74 \%$ reported avoiding intercourse (Supplement D). The next most common answer (19\%) was withdrawal, followed by using condoms or another barrier method ( $16 \%$ among rhythm users, and $13 \%$ among SDM users), and EC (12\% among rhythm users and $11 \%$ among SDM users).

The majority $(64 \%)$ of FABM users who abstained from sex during the fertile window reported that it was "very easy" to get their partner to abstain on these days, with another $22 \%$ reporting that it was somewhat easy. Only $14 \%$ reporting that this was somewhat or very hard. Among FABM users who reported using withdrawal during fertile days, $68 \%$ said very easy, $10 \%$ somewhat easy, and $22 \%$ somewhat or very hard. We asked a similar question about condom use, but an ODK programming error precluded calculating estimates for this question.

When FABM users were asked whether menstruation affects sexual activity with their partner, $76 \%$ said "yes, we generally avoid sex when I am menstruating," but $20 \%$ stated, "no, because we don't have sex regularly." Only $4 \%$ responded, "no, we generally have sex when I am menstruating."

\section{DISCUSSION}

We posit that at least $18 \%$ of contracepting women in Ghana likely relied primarily on an FABM for pregnancy prevention. Had we relied on the most effective method reported, as is standard procedure, the estimate would be $13.5 \%$ (9.2\% rhythm, 4.3\% SDM). Our 18\% estimate likely represents a lower bound, because, like the 2014 Ghana DHS ${ }^{47}$ and 2017 Ghana Maternal Health Survey, ${ }^{48}$ we used a filtering question. ${ }^{\dagger}$ However, unlike those surveys, among women who acknowledged ever or currently doing something or using a method to prevent pregnancy, our survey asked about all methods. Also, unlike those surveys, we assessed patterns of multiple method use to ascertain likely FABM users.

Our rhythm prevalence estimates (based on most effective method) were slightly lower than those from the 2017 Ghana Maternal Health Survey for all women, currently married women, and sexually active unmarried women (Supplement A). This may be because SDM users may have reported themselves as rhythm users in that survey; combining our rhythm and SDM estimates results in estimates similar to estimates for

${ }^{\dagger}$ As described in the methods section, the filtering question excluded women who do not perceive themselves as "doing anything or using any method torhythm in that surdelay or avoid getting pregnant." vey. Overall, based 
on our estimate that $18 \%$ of contracepting Ghanaian women likely rely primarily on an FABM, we estimate that a minimum of 343,890 Ghanaian women (of an estimated 1,899,943 Ghanaian female contraceptors) currently rely primarily on an $\mathrm{FABM}^{49}$; a larger number than those using oral contraceptive pills or using male condoms, and nearly as many as those using 3-monthly injectables.

Among FABM users, more than half $(57 \%)$ reported currently using only their FABM, while the remainder also reported current use of condoms, withdrawal, EC, and/or other methods. Prior studies in Ghana suggest that such contraceptive "mosaics" of methods that are viewed as natural are common. These methods are believed to help protect the regular flow of menses from bleeding changes induced by other methods ${ }^{50}$ as bleeding changes are perceived as linked with infertility. ${ }^{7,51-53}$ These contraceptive patterns have implications for how FABM prevalence is calculated in large-scale surveys and merits reexamination of the use of terms like "periodic abstinence" and the definition of "rhythm" currently used in DHS and other survey questions. For example, the Ghana 2017 Maternal Health Survey describes rhythm as "to avoid pregnancy, women do not have sexual intercourse on the days of the month they think they can get pregnant"; this definition inaccurately implies that rhythm is always practiced with abstinence. We elaborate upon this concern in Supplement E, where we advocate that the term "periodic abstinence" be replaced with a less assumption-laden term, such as "fertility awareness-based method." Similarly, we describe how language used to describe FABMs to respondents should be revised to avoid the assumption of abstinence during the fertile time.

Contraceptors who reported currently using FABMs (versus IUDs or hormonal methods) appeared to have several relatively advantaged characteristics: after controlling for multiple sociodemographic factors, they are more likely to be older, richer, more educated, and to have fewer children. This corroborates other findings from Ghana, in which contraceptors who were older, urban, more educated, and had fewer children were more likely to choose a traditional instead of modern method, ${ }^{12}$ though these patterns do not necessarily hold in other countries. ${ }^{11}$ Use of FABMs by relatively advantaged women may reflect distinct preferences for these methods, as identified in other Ghanaian studies ${ }^{10,13}$ and elsewhere $^{8,9}$ or may reflect that aspects of FABMs may be less accessible to more disadvantaged women (e.g., power differentials negating an ability to negotiate the timing and circumstances of sexual activity with a partner, which women in our sample did not report particular difficulty in doing). Though only borderline statistically significant in our multivariable model, correct knowledge of the approximate fertile time did appear to be higher among likely FABM users, which has been observed previously in Ghana, ${ }^{48}$ yet only $50 \%$ of FABM users correctly identified the approximate fertile time, indicating substantial room for improvement among individuals relying upon this information to prevent pregnancy.

The majority $(85 \%)$ of rhythm users reported identifying fertile and nonfertile days using a calendar, though it remains unclear exactly what rules they used to determine fertile and infertile days. Many were likely not using the formal rules of the rhythm method and may have simply avoided unprotected sex on days when they believed-possibly inaccurately-that pregnancy was possible. ${ }^{16}$ In Supplement E, we elaborate upon impreciseness in current use of the term "rhythm," which has come to be used as a generic word for a diverse array of nonformalized practices, ${ }^{54}$ perhaps better described as "informal rhythm." Furthermore, less than a quarter of rhythm users had heard of ways to make FABM use easier, and few reported using tools like CycleBeads or apps indicated for pregnancy prevention. Yet, nearly all rhythm users expressed interest in learning how to make use of their method more effective, and a substantial proportion of rhythm users expressed willingness to collect additional biomarkers (i.e., temperature, cervical mucus, cervical position) or to use tools such as mobile phone apps. Given that only $17 \%$ of rhythm users had ever discussed use of the rhythm method with a health professional, there appears to be a substantial missed opportunity to assist rhythm users in identifying ways to improve the effectiveness of their chosen contraceptive method.

This missed opportunity has also been reflected in prior work in Ghana. For example, in a small $(n=85)$ survey in central Ghana conducted in 2010 on contraceptive self-care options, only $36 \%$ of respondents indicated interest in selfadministered injections, but $75 \%$ indicated wanting to learn more about FABMs. ${ }^{55}$ In a monitoring study of a free FABM app, $60.8 \%$ of Ghanaian women who downloaded the app for the purpose of pregnancy prevention were not using a method of contraception in the prior 3 months, and

\section{Given that only $17 \%$ of rhythm users had ever discussed using the method with a health professional, there appears to be a substantial missed opportunity to assist users in identifying ways to improve the effectiveness of their chosen contraceptive method.}


$23 \%$ noted that it was the first method they had ever used, ${ }^{26}$ suggesting that FABMs may attract new users. Researchers have recommended that family planning programs in Ghana consider the promotion of modern FABMs along with other modern methods, ${ }^{55,56}$ which would require health professionals (particularly community health nurses and midwives who commonly offer and provide family planning methods in Ghana) to be trained to offer FABMs. Furthermore, certain FABMs (e.g., CycleBeads) require commodities, but to the best of our knowledge, nationally representative, facility-based, reproductive health commodities and service surveys in Ghana funded by United Nations Population Fund have not included FABM-related commodities when assessing the availability of modern methods at service delivery points.

Strengths of this study include the use of a nationally representative sample of Ghanaian women and the incorporation of probing on the ever or current use of all methods of contraception. This builds upon an approach used by Rossier et al. in Burkina Faso, wherein investigators probed on all traditional methods. ${ }^{33}$ Finally, as far as we are aware, this is one of the first studies in a low- or middle-income country to ask detailed questions on FABM use, eliciting information that could be used to inform better outreach to and counseling for rhythm method users, who appear to be interested in understanding how to improve the effectiveness of their chosen contraceptive method.

\section{Limitations}

Our study has multiple limitations, key among them being that our prevalence estimates suffer from some of the same methodological flaws as other nationally representative studies in Ghana, given that we used a filtering question in asking about method use, which may lead to underreporting of FABMs and other methods. We believe this would have been more impactful in soliciting "ever" use (vs. current use). If a participant acknowledged having ever used any method, interviewers would eventually ask about all methods, priming the respondent (before answering the current method question), that rhythm and SDM "count" as contraceptive methods. In addition, we did not specifically ask about the use of FABMs other than rhythm or SDM in our survey, which could potentially mean that users of methods such as TwoDay, symptothermal, or others are undercounted; however, we expect this to be highly unlikely, particularly given the responses to questions on knowledge of other FABMs. One of our questions on rhythm suffered from the same definitional errors as seen in other large-scale survey questions on rhythm. Specifically, one of our questions asked, "You noted that you use the rhythm method, or avoiding sex on days when you are more likely to get pregnant. Can you please state all of the ways in which you identify your fertile and non-fertile days?" The implicit assumption that rhythm users abstain from sexual activity on days they believe they are more likely to get pregnant should be discontinued in survey research on FABMs, as described above and elaborated upon in Supplement E. We do not know whether Ghanaian women who refer to their practice as "counting days" (as identified in other studies ${ }^{34}$ ) would label themselves as a rhythm user, an SDM user, a nonuser, or something else. Supplement E also highlights that the way in which users of specific FABMs (such as SDM, symptothermal method, etc.) are classified in DHS may depend upon whether the survey specifically asks about these methods or not; a point which researchers should be cognizant of when analyzing survey data.

Future surveys might more deeply investigate the use of menstrual trackers and how they are perceived, as well as examine whether variables not available in our data (i.e., distance to health facility) may be associated with FABM use. Finally, as noted previously, ${ }^{46}$ our approach to FABM prevalence estimation assumes that women reporting multiple contraceptive methods use them in conjunction with one another (rather than that, for example, a user was switching permanently from an FABM to condom use during the month of interview). Another complexity of understanding patterns of multiple method use is that our labeling of individuals being "primarily" FABM users is somewhat subjective; such users may perceive their "primary" method to be condoms or EC, for example, even if the FABM is being "used" throughout the cycle and condoms or EC are being used episodically during periods believed to be infertile.

\section{CONCLUSION}

Our study indicates that a nontrivial proportion of reproductive age Ghanaian contracepting women $(18 \%)$ are using a traditional or modern FABM (rhythm or SDM); more than those who report using oral contraceptive pills and nearly as many as report using 3-monthly injectables. Findings reiterate that standard approaches to measuring these methods underestimate their use, but additional survey methodological changes are required to further improve the accuracy of FABM use 
estimates. Results showed that more advantaged women were more likely to be using an FABM, suggesting that FABM use among this population may be a preference and not simply a lack of access to alternative options. Understanding these choices can help to support client-centered contraceptive counseling and programs for women and couples interested in using these methods. As side effects and health concerns are increasingly the main reasons for contraceptive nonuse in low- and middleincome countries, FABMs may offer an approach to pregnancy prevention to women whose contraceptive needs are not met by other options. ${ }^{12}$ Family planning programs should work to respectfully address these needs as part of a commitment to reproductive autonomy and choice.

Acknowledgments: We are grateful to our entire fielding team and all study participants.

Funding: This study was made possible by United Kingdom Aid from the United Kingdom Government and a grant from the Dutch Ministry of Foreign Affairs.

Disclaimer: The views expressed are those of the authors and do not necessarily reflect the positions and policies of the donors.

Author contributions: CBP led the conceptualization of the analysis, programmed the analytical code and conducted the analysis, and verified the overall reproducibility of the results. CBP and SOB managed and cleaned data. EO and RL-R led data collection efforts. CBP, EO, SOB, and RL-R provided resources in terms of study materials, contact with respondents, and computing resources. CBP wrote the original draft of the manuscript. CBP, EO, SOB, and RL-R participated in reviewing and editing the draft.

Data availability: De-identified versions of the Community-Based Survey collected by the authors and used in this analysis are available from the Guttmacher Institute upon reasonable request to researchers who wish to use the data for scholarly analysis. To discuss obtaining copies of these datasets, please contact popcenter@guttmacher.org with the detailed protocol for your proposed study, and information about the funding and resources you have to carry out the study.

Competing interests: None declared.

\section{REFERENCES}

1. Urrutia RP, Polis CB. Fertility awareness based methods for pregnancy prevention. BMJ. 2019;366:14245. CrossRef. Medline

2. Bradley SEK, Polis CB, Bankole A, Croft T. Global contraceptive failure rates: who is most at risk? Stud Fam Plann. 2019;50(1):3-24. CrossRef. Medline

3. Madden T, Secura GM, Nease RF, Politi MC, Peipert JF. The role of contraceptive attributes in women's contraceptive decision making. Am J Obstet Gynecol. 2015;213(1):46.e 1-46.e6. CrossRef. Medline

4. Lessard LN, Karasek D, Ma S, et al. Contraceptive features preferred by women at high risk of unintended pregnancy. Perspect Sex Reprod Health. 2012;44(3):194-200. CrossRef. Medline

5. Donnelly KZ, Foster TC, Thompson R. What matters most? The content and concordance of patients' and providers' information priorities for contraceptive decision making. Contraception. 2014;90(3):280-287. CrossRef. Medline

6. Peipert JF, Madden T, Allsworth JE, Secura GM. Preventing unintended pregnancies by providing no-cost contraception. Obstet Gynecol. 2012;120(6):1291-1297. CrossRef. Medline

7. Polis $C B$, Hussain R, Berry A. There might be blood: a scoping review on women's responses to contraceptive-induced menstrual bleeding changes. Reprod Health. 2018;15(1):114. CrossRef. Medline

8. Basu AM. Ultramodern contraception. Asian Popul Stud. 2005; (3):303-323. CrossRef

9. Johnson-Hanks J. On the modernity of traditional contraception: time and the social context of fertility. Popul Dev Rev. 2002;28(2):229249. CrossRef

10. Machiyama K, Cleland J. Unmet need for family planning in Ghana: the shiffing contributions of lack of access and attitudinal resistance. Stud Fam Plann. 2014;45(2):203-226. CrossRef. Medline

11. Rossier C, Corker J. Contemporary use of traditional contraception in sub-Saharan Africa. Popul Dev Rev. 2017;43(Suppl 1):192-215. CrossRef. Medline

12. Gebreselassie T, Bietsch K, Staveteig S, Pullum T. Trends, Determinants, and Dynamics of Traditional Contraceptive Method Use. ICF; 2017

13. Staveteig S. Fear, opposition, ambivalence, and omission: results from a follow-up study on unmet need for family planning in Ghana. PLoS One. 2017;12(7):e0182076. CrossRef. Medline

14. Sedgh G, Ashoford LS, Hussain R. Unmet Need for Contraception in Developing Countries: Examine Women's Reasons for Not Using a Method. Guttmacher Institute; 2016. Accessed May 24, 2021. https://www.guttmacher.org/sites/default/files/report_pdf/ unmet-need-for-contraception-in-developing-countries-report.pdf

15. Bradley SE, Schwandt H, Khan S. Levels, Trends, and Reasons for Contraceptive Discontinuation. DHS Analytical Studies 20. ICF Macro; 2009. Accessed May 24, 2021. http://cedar.wwu.edu/ fairhaven_facpubs/1/

16. Che Y, Cleland JG, Ali MM. Periodic abstinence in developing countries: an assessment of failure rates and consequences. Contraception. 2004;69(1):15-21. CrossRef. Medline

17. Festin MPR, Kiarie J, Solo J, et al. Moving towards the goals of FP2020 - classifying contraceptives. Contraception. 2016;94 (4):289-294. CrossRef. Medline

18. Malarcher S, Spieler J, Fabic MS, Jordan S, Starbird EH, Kenon C. Fertility awareness methods: distinctive modern contraceptives. Glob Health Sci Pract. 2016;4(1):13-15. CrossRef. Medline

19. Austad K, Chary A, Colom A, et al. Fertility awareness methods are not modern contraceptives: defining contraception to reflect our priorities. Glob Health Sci Pract. 2016;4(2):342-345. CrossRef. Medline

20. Marston C, Church K. Response to Letters to the Editor from Irit Sinai "Standard Days Method Effectiveness: opinion disguised as scientific review" and Kelsey Wright, Karen Hardee, and John Townsend "The piffalls of using selective data to represent the effectiveness, relevance and utility of the Standard Days Method of contraception". Contraception. 2016;94(4):376-378. CrossRef. Medline

21. Hubacher D, Trussell J. A definition of modern contraceptive methods. Contraception. 2015;92(5):420-421. CrossRef. Medline

22. U.S. Food \& Drug Administration. FDA allows marketing of first direct-to-consumer app for contraceptive use to prevent pregnancy. Published August 10, 2018. Accessed May 24, 2021. https://www. fda.gov/news-events/press-announcements/fda-allows-marketingfirst-direct-consumer-app-contraceptive-use-prevent-pregnancy

23. U.S. Food \& Drug Administration. Clue birth control. In 510(k) Premarket Notification [database online]. Updated May 24, 2021. 
Accessed May 24, 2021. https://www.accessdata.fda.gov/scripts/ cdrh/cfdocs/cfpmn/pmn.cfm?ID=K193330

24. Starling MS, Kandel Z, Haile L, Simmons RG. User profile and preferences in fertility apps for preventing pregnancy: an exploratory pilot study. mHealth. 2018;4:21-21. CrossRef. Medline

25. Duane M, Contreras A, Jensen ET, White A. The performance of fertility awareness-based method apps marketed to avoid pregnancy. J Am Board Fam Med. 2016;29(4):508-511. CrossRef. Medline

26. Haile LT, Fultz HM, Simmons RG, Shelus V. Market-testing a smartphone application for family planning: assessing potential of the CycleBeads app in seven countries through digital monitoring. mHealth. 2018;4:27-27. CrossRef. Medline

27. Weis J, Festin M. Implementation and scale-up of the Standard Days Method of family planning: a landscape analysis. Glob Health Sci Pract. 2020;8(1):114-124. CrossRef. Medline

28. Shelus V, Ashcroft N, Burgess S, Giuffrida M, Jennings V. Preventing pregnancy in Kenya through distribution and use of the CycleBeads mobile application. Int Perspect Sex Reprod Health. 2017;43 (3):131-141. CrossRef. Medline

29. Ashcroft N, Shelus V, Garg H, McLarnon-Silk C, Jennings VH. Implementation of CycleTel Family Advice: an SMS-based service to provide family planning and fertility awareness information in India. mHealth. 2017;3:20. CrossRef. Medline

30. Igras S, Sinai I, Mukabatsinda M, Ngabo F, Jennings V, Lundgren $R$. Systems approach to monitoring and evaluation guides scale up of the Standard Days Method of family planning in Rwanda. Glob Health Sci Pract. 2014;2(2):234-244. CrossRef. Medline

31. Arévalo $M$, Jennings $V$, Nikula $M$, Sinai I. Efficacy of the new TwoDay Method of family planning. Fertil Steril. 2004;82(4):885892. CrossRef. Medline

32. Kavanaugh ML, Jerman J. Contraceptive method use in the United States: trends and characteristics between 2008, 2012 and 2014. Contraception. 2018;97(1):14-21. CrossRef. Medline

33. Rossier C, Senderowicz L, Soura A. Do natural methods count? Underreporting of natural contraception in urban Burkina Faso. Stud Fam Plann. 2014;45(2):171-182. CrossRef. Medline

34. Marston C, Renedo A, Nyaaba GN, Machiyama K, Tapsoba P, Cleland J. Improving the measurement of fertility regulation practices: findings from qualitative research in Ghana. Int Perspect Sex Reprod Health. 2017;43(3):111-1 19. CrossRef. Medline

35. Staveteig S. Understanding Unmet Need in Ghana: Results From a Follow-up Study to the 2014 Ghana Demographic and Health Survey. DHS Qualitative Research Studies No. 20. ICF International 2016. Accessed May 24, 2021. https://www.dhsprogram.com/ pubs/pdf/QRS20/QRS20.pdf

36. Nanda K, Lebetkin E, Steiner MJ, Yacobson I, Dorflinger $\amalg$. Contraception in the era of COVID-19. Glob Health Sci Pract. 2020;8(2):166-168. CrossRef. Medline

37. Purdy C. Opinion: How will COVID-19 affect global access to contraceptives - and what can we do about it? Devex. Published March 11, 2020. Accessed May 24, 2021. https:// www.devex.com/news/sponsored/opinion-how-will-covid19-affect-global-access-to-contraceptives-and-what-can-wedo-about-it-96745

38. Brady M, Drake JK, Namagembe A, Cover J. Self-care provision of contraception: evidence and insights from contraceptive injectable self-administration. Best Pract Res Clin Obstet Gynaecol. 2020;66:95-106. CrossRef. Medline

39. Iyanda AE, Dinkins BJ, Osayomi T, Adeusi TJ, Lu Y, Oppong JR Fertility knowledge, contraceptive use and unintentional pregnancy in 29 African countries: a cross-sectional study. Int J Public Health 2020;65(4):445-455. CrossRef. Medline

40. Delbaere I, Verbiest S, Tydén T. Knowledge about the impact of age on fertility: a brief review. Ups J Med Sci.2020;125(2):167-174. CrossRef. Medline

41. Polis CB. Published analysis of contraceptive effectiveness of Daysy and DaysyView app is fatally flawed. Reprod Health. 2018;15 (1):113. CrossRef. Medline

42. Polis $C B$, Otupiri $E$, Hindin $M$, et al. Prevalence and correlates of perceived infertility in Ghana. Stud Fam Plann. 2020;51(3):207224. CrossRef. Medline

43. Keogh SC, Otupiri E, Chiu DW, et al. Estimating the incidence of abortion: a comparison of five approaches in Ghana. BMJ Glob Health. 2020;5(4):e002129. CrossRef. Medline

44. Keogh SC, Otupiri E, Castillo PW, et al. Hormonal contraceptive use in Ghana: the role of method attributes and side effects in method choice and continuation. Contraception. 2021;S0010-7824(21) 0015107. CrossRef. Medline

45. Sheon AR, Stanton C. Use of periodic abstinence and knowledge of the fertile period in 12 developing countries. Int Fam Plan Perspect. 1989;15(1):29-34. CrossRef

46. Polis CB, Jones RK. Multiple contraceptive method use and prevalence of fertility awareness based method use in the United States, 2013-2015. Contraception. 2018;98(3):188-192. CrossRef. Medline

47. Ghana Statistical Service (GSS), Ghana Health Service (GHS) ICF International. Ghana Demographic and Health Survey 2014. GSS, GHS, ICF International; 2015. Accessed May 24, 2021. https://www.dhsprogram.com/pubs/pdf/FR307/ FR307.pdf

48. Ghana Statistical Service (GSS), Ghana Health Service (GHS), ICF Ghana Maternal Health Survey 2017. GSS, GHS, and ICF; 2018. Accessed May 24, 2021. https://dhsprogram.com/pubs/pdf/ FR340/FR340.pdf

49. Ghana Statistical Service (GSS). Projected Population by Age and Sex, 260 Districts, 2020. GSS; 2020. Accessed May 24, 2021. https://www.statsghana.gov.gh/infobankdetails.php?infobank= NzM4OTU5NzcwLiU0Mg==/infodesk/5ss09qq33r

50. Marston C, Renedo A, Nyaaba GN. Fertility regulation as identity maintenance: Understanding the social aspects of birth control. $J$ Health Psychol. 2018;23(2):240-251. CrossRef. Medline

51. Osei IF, Mayhew SH, Biekro L, Collumbien M; ECAF Team. Fertility decisions and contraceptive use at different stages of relationships: windows of risk among men and women in Accra. Int Perspect Sex Reprod Health. 2014;40(03):135-143. CrossRef. Medline

52. Hindin MJ, McGough LJ, Adanu RM. Misperceptions, misinformation and myths about modern contraceptive use in Ghana: Table 1. J Fam Plann Reprod Health Care. 2014:40(1):30-35. CrossRef. Medline

53. Atijosan A, Adeyeye $O$, Ogungbayi $O$. Knowledge and perception regarding infertility among university students in lle-Ife: a view through gender lens. Covenant J Bus Soc Sci. 2019;10(1):14. CrossRef

54. Jennings $\mathrm{VH}$, Polis $\mathrm{CB}$. Fertility awareness-based methods. In: Hatcher RA, Nelson AL, Trussell J, et al., eds. Contraceptive Technology. 21 st ed. Ayer Company Publishers, Inc.; 2018

55. Krakowiak-Redd D, Ansong D, Otupiri E, et al. Family planning in a sub-district near Kumasi, Ghana: side effect fears, unintended pregnancies and misuse of a medication as emergency contraception. Afr J Reprod Health. 2011;15(3):121-132. Medline

56. Eliason S, Baiden F, Yankey BA, Awusabo-Asare K. Determinants of unintended pregnancies in rural Ghana. BMC Pregnancy Childbirth. 2014;14(1):261. CrossRef. Medline 


\section{Peer Reviewed}

Received: October 16, 2020; Accepted: May 11, 2021; First published online: June 17, 2021.

Cite this article as: Polis CB, Otupiri E, Bell SO, Larsen-Reindorf R. Use of fertility awareness-based methods for pregnancy prevention among Ghanaian women: a nationally representative cross-sectional survey. Glob Health Sci Pract. 2021;9(2):318-331. https://doi.org/10.9745/GHSPD-20-00601

(C) Polis et al. This is an open-access article distributed under the terms of the Creative Commons Attribution 4.0 International License (CC BY 4.0), which permits unrestricted use, distribution, and reproduction in any medium, provided the original author and source are properly cited. To view a copy of the license, visit https://creativecommons.org/licenses/by/4.0/. When linking to this article, please use the following permanent link: https://doi. org/10.9745/GHSP-D-20-00601 